University of Nebraska - Lincoln

DigitalCommons@University of Nebraska - Lincoln

Faculty Publications, Department of Psychology

Psychology, Department of

January 2008

\title{
Competition Between the Conditioned Rewarding Effects of Cocaine and Novelty
}

Carmela M. Reichel

University of Nebraska-Lincoln

Rick A. Bevins

University of Nebraska-Lincoln, rbevins1@unl.edu

Follow this and additional works at: https://digitalcommons.unl.edu/psychfacpub

Part of the Psychiatry and Psychology Commons

Reichel, Carmela M. and Bevins, Rick A., "Competition Between the Conditioned Rewarding Effects of Cocaine and Novelty" (2008). Faculty Publications, Department of Psychology. 319.

https://digitalcommons.unl.edu/psychfacpub/319

This Article is brought to you for free and open access by the Psychology, Department of at DigitalCommons@University of Nebraska - Lincoln. It has been accepted for inclusion in Faculty Publications, Department of Psychology by an authorized administrator of DigitalCommons@University of Nebraska - Lincoln. 
Published in Behavioral Neuroscience 122:1 (2008), pp. 140-150; doi 10.1037/0735-7044.122.1.140

Copyright (C) 2008 by the American Psychological Association. Used by permission. "This article may not exactly replicate the final version published in the APA journal. It is not the copy of record."

Submitted May 25, 2007; revised September 26, 2007; accepted September 27, 2007

The authors thank Victoria Hall and Clint Waltman for assistance scoring the videotapes. This research was partially supported by NIH research Grant DA017086. R. A. Bevins was partially supported by DA018114 while preparing this manuscript for publication.

Correspondence concerning this article should be addressed to Rick A. Bevins, Department of Psychology, 238 Burnett Hall, University of Nebraska-Lincoln, Lincoln, NE 68588-0308. email: rbevins1@unl.edu

\title{
Competition Between the Conditioned Rewarding Effects of Cocaine and Novelty
}

\author{
Carmela M. Reichel and Rick A. Bevins \\ Department of Psychology, University of Nebraska-Lincoln
}

\begin{abstract}
Access to novelty might provide an alternative learning history that competes with conditioned drug reward. We tested this suggestion in rats using a place conditioning procedure with cocaine and novelty. In Experiment 1, rats were conditioned with cocaine to prefer one side of an apparatus. In a subsequent phase, cocaine exposure continued; however, on the unpaired side, separate group of rats had access to novel objects, cocaine injections, or saline with no objects. Pairings with novel objects or cocaine shifted a preference away from the cocaine-paired environment during drug-free and drug-challenge tests. Experiment 2 tested novelty's impact when cocaine exposure was discontinued. The identical procedures were used, except drug exposure ceased on the cocaine-paired side during the second phase. Both groups expressed a preference for the cocaine compartment. This preference was maintained for rats that did not have novel objects; however, rats that experienced novelty spent similar amounts of time in both compartments during both tests. Overall, the conditioned rewarding effects of novelty competed with those of cocaine as evidenced by a change in choice behaviors motivated by drug reward.
\end{abstract}

Keywords: reward competition, novelty seeking, sensation seeking, conditioned place preference, natural rewards

Individuals that tend to seek out novel and high-risk situations (i.e., high sensation seekers) also report more drug use and respond better to anti-drug ads targeted at this noveltyseeking tendency (Palmgreen, Donohew, Lorch, Hoyle, \& Stephenson, 2001; Stephenson, 2003; Zuckerman \& Kuhlman, 2000). Researchers and theorists have attributed this correlation between sensation/novelty seeking and drug use to an overlap in the rewarding effects of novelty and drugs (Bardo, Donohew, \& Harrington, 1996; Bardo \& Dwoskin, 2004; Bevins, 2001). This attribution has important implications for drug abuse intervention strategies and is supported by preclinical animal research examining parallel effects (Cain, Saucier, \& Bardo, 2004; Dellu et al., 1996). For instance, access to novelty or abused drugs can enhance unconditioned and conditioned locomotor activity, reinforce and maintain behavior, produce preferences for places associated with its access, and increase extracellular dopamine levels in the nucleus accumbens (Bevins \& Bardo, 1999; Bevins et al., 2002; Mueller \& Stewart, 2000; Rebec, Grabner, Johnson, Pierce, \& Bardo, 1996; Wise \& Bozarth, 1987). Further, placement in a novel environment or presentation of novel stimuli can decrease drug intake and access to a novel object can potentiate the rewarding effects of a low dose of cocaine (Bevins, 2001; Cain, Smith, \& Bardo, 2004; Thompson \& Ostlund, 1965).

Drug users often report that exposure to drug paraphernalia, videos of purchasing drugs, and imagery of drug use evoke feelings of drug craving during abstinence from cocaine (Ehrman et al., 1992; Kilts et al., 2001; Robbins et al., 1997). These associations formed between the physiological ef- fects of abused drugs and cues in the drug-taking environment are likely because of Pavlovian conditioning (Di Chiara, 1999; Koob \& LeMoal, 2000; Robinson \& Berridge, 2001). In the case of drug conditioning, environmental cues (conditioned stimulus, CS) presented in close temporal proximity with the physiological effects of the drug (unconditioned stimulus, US) come to evoke behavioral, cognitive, and physiological responses even in a nondrug state (Ehrman et al., 1992; Kilts et al., 2001; Robbins et al., 1997; Sell et al., 2000). These conditioned associations are thought to be critical factors in the acquisition and maintenance of drug-taking behavior, as well as contributing to the high incidences of relapse (Anagnostaras \& Robinson, 1996; Di Chiara, 1999; Robinson \& Berridge, 2001; Shaham et al., 2003).

The main interests in this research are the interactions between cocaine- and novelty-conditioned rewards. The most commonly used index of reward in rodents is the place conditioning procedure (Bardo \& Bevins, 2000; Bevins \& Cunningham, 2006; Tzschentke, 1998). In this procedure, rats are repeatedly exposed to two distinct environments. A biologically and motivationally rewarding stimulus (e.g., cocaine, novelty, food, water) is provided in one environment but not in the other. On test day, the rat is given a choice between the two environments-typically in the absence of the reward. In most place conditioning preparations, exteroceptive cues of the paired environment become associated with the rewarding aspects of the stimuli of interest. Accordingly, the paired environment acquires appetitive value, thus, eliciting approach behaviors (Bardo \& Bevins, 2000; Panksepp et 
al., 2004). This approach behavior is expressed as an increase in the amount of time spent in the paired environment during the choice test.

Although the place-conditioning task is most often considered a measure of conditioned drug reward, it is also a way to study the impact of learning history on choice behavior (Bardo \& Bevins, 2000). In regards to drug abuse, the associations formed between exteroceptive cues and the rewarding effects of drugs influence choices people make about drug use. Preclinical models can compare the impact of conditioned associations on choice behavior with a variation of the traditional place conditioning procedure termed a "reference-conditioning" procedure. Rather than comparing reward to no reward (e.g., a drug to saline), as typically done, a reference-conditioning procedure compares a known rewarding stimulus (e.g., cocaine) to some other value of the same stimulus or to a different stimulus (e.g., another cocaine dose or different drug) (Barr et al., 1985; Bevins, 2005; Bevins \& Cunningham, 2006). This procedural variation allows comparisons to be made between the conditioned rewarding values of two different stimuli using a common preclinical screen for drug reward. In terms of drug abuse prevention and intervention strategies, qualitatively different types of reward (e.g., cocaine vs. novelty) can be compared using this reference-conditioning procedure (cf. Bevins, 2005; Mattson et al., 2001).

As mentioned previously, the behavioral and neurobiological processes underlying the pleasurable aspects of novelty appear to overlap with those of other rewards (Bardo, Donohew, \& Harrington, 1996; Bardo \& Dwoskin, 2004; Bevins, 2001; Bevins \& Bardo, 1999; Bevins et al., 2002; Cain, Saucier, \& Bardo, 2005; Dellu et al., 1996; Rebec et al., 1996). In a place conditioning preparation, conditioned responding is expressed similarly to cocaine and novel objects (Besheer \& Bevins, 2003; Bevins, 2001; Bevins \& Bardo, 1999; Douglas, Varlinskaya, \& Spear, 2003; McBride et al., 1999; Mueller \& Stewart, 2000). Additionally, drugs that block place conditioning to cocaine (e.g., SCH-23390) also block novelty-conditioned and novelty-induced preferences (Bardo et al., 1993; Besheer et al., 1999; Bevins \& Bardo, 1999; Cervo \& Sarnanin, 1995). Access to a novel object can also potentiate a place preference to a sub-threshold dose of cocaine (Bevins, 2001). The preponderance of this research demonstrates that novelty simulates or summates with drug reward. Although this research has speculated that the conditioned rewarding effects of cocaine and novelty could compete, this prediction has not been directly tested in a choice situation until this present set of experiments.

\section{General Method}

\section{Subjects}

Subjects were 58 experimentally naïve male rats of SpragueDawley descent (Harlan Industries, Indianapolis, IN) weighing 250-275 $\mathrm{g}$ at the time of delivery. Rats were individually housed in plastic tubs in a colony room at $22-24^{\circ} \mathrm{C}$ maintained on a 12:12 light:dark cycle. Food and water were continuously available in the home cage. Experimental protocols were approved by the University of Nebraska-Lincoln Institutional Animal Care and Use Committee and followed the "Guide for the Care and Use of Laboratory Animals" (National Research Council, 1996).

\section{Apparatus}

Place conditioning was assessed in two Plexiglas and aluminum chambers that have two distinct compartments separated by a smaller placement area. The two end compartments measured $42 \times 16 \times 20 \mathrm{~cm}(1 \times \mathrm{w} \times \mathrm{h})$; the center compartment measured $11.5 \times 15.5 \times 18.5 \mathrm{~cm}(\mathrm{l} \times \mathrm{w} \times \mathrm{h})$. Interchangeable floors were used to create the distinct environments. One floor had approximately $3401.3 \mathrm{~cm}$ holes drilled into a 16-gauge aluminum sheet. The other floor had 1-cm rods made from stainless steel. Two rods were mounted side by side on an acrylic base with the following adjacent rod pair separated from the first pair by $1 \mathrm{~cm}$. Each sequential pair of rods was separated by $1 \mathrm{~cm}$. The novel objects used were a white sock (about 40 cm long), a white PVC pipe (8 cm long; $10.5 \mathrm{~cm}$ diameter), a plastic scouring pad ( $9 \mathrm{~cm}$ diameter) attached to a paint roller (7.5 cm long, $4 \mathrm{~cm}$ diameter), and a sheet of newspaper wadded into a ball (cf. Bevins et al., 2002).

\section{Drugs}

(-)-Cocaine hydrochloride, a gift from NIDA or purchased from Sigma Chemicals (St. Louis, MO), was dissolved in saline $(0.9 \% \mathrm{NaCl})$ and injected intraperitoneally at a volume of $1 \mathrm{ml} / \mathrm{kg}$.

\section{Statistical Analysis}

Dependent measures. Time spent in each compartment was the primary dependent measure during habituation and all ensuing test sessions. All test sessions were videotaped for later observations. A rat was considered in a specific compartment when forelegs, head, and shoulders were positioned inside the compartment. Interobserver reliability on this behavior was conducted by an observer naïve to the experimental conditions (see Besheer, Jensen, \& Bevins, 2002). Data were converted to a preference ratio with the following formula: (time spent in cocaine-paired compartment)/(time spent in cocainepaired compartment + time spent in opposite compartment). A preference score of 0.5 indicates lack of a compartment preference; a value greater than 0.5 indicates a preference for the initial compartment paired with cocaine.

We also evaluated horizontal activity in each end compartment. Horizontal activity was defined as the number of times the rat's front paws crossed a center line that bisected the end compartment. Activity (number of line crosses/seconds spent in compartment) was compared for the cocaine-paired and opposite side on habituation and place conditioning test days.

Data analyses. During habituation, the time spent and activity scores in each of the two distinct compartments (i.e., comparison between rods and holes) were analyzed by a twoway (Group $\times$ Floor type) mixed analysis of variance (ANOVA) to demonstrate the unbiased construction of our apparatus. To ascertain the relative effectiveness of competing rewards on choice behavior (i.e., time in each compartment) we first conducted a separate two-way (Side $\times$ Test day) within subjects ANOVAs for each group across the three test days; a similar analysis was conducted on activity data. To determine shifts in compartment preference across groups we then compared preference ratios (see Dependent Measures) with a two-way (Group $\times$ Test) mixed ANOVAs. Additionally, a test for conditioned hyperactivity was conducted with activity data from 
the habituation session and the initial cocaine test day. Specifically, conditioned hyperactivity was analyzed using three-way [Side (paired and unpaired) $\times$ Test Day (habituation and cocaine test day) $\times$ Group] mixed ANOVAs. Follow up comparisons used Tukey HSD tests to control for Type I error rate. Statistical significance was declared using a two-tailed rejection region of 0.05 for all tests.

\section{Experiment 1}

\section{Competition Between Cocaine and Novelty Conditioned Reward Procedure}

\section{Habituation}

On the habituation day, rats were placed in the center compartment and allowed free access to the two end compartments for $10 \mathrm{~min}$. This test confirmed the unbiased construction of the apparatus and provided experience with the later testing procedure. Rats were assigned to conditioning groups in an unbiased fashion (cf. Bevins \& Cunningham, 2006).

\section{Cocaine Place Conditioning}

Compartment placement was counterbalanced according to rods/holes, spatial orientation, and whether drug pairing occurred on the first or second day of conditioning (Bevins \& Cunningham, 2006). On Day 1 of conditioning, half of the rats were restricted to the compartment with rod floors and the remaining rats were restricted to the compartment with hole floors for $30 \mathrm{~min}$. Rats placed in their paired compartment were injected with cocaine $(7.5 \mathrm{mg} / \mathrm{kg})$ immediately before placement, whereas rats placed in their unpaired compartment were injected with saline. On Day 2 of conditioning, rats were restricted to the opposite compartment for $30 \mathrm{~min}$. Rats previously injected with cocaine-received saline, whereas rats previously injected with saline received cocaine. Conditioning lasted 8 days with alternating daily placements in the two end compartments of the apparatus; these placements were separated by $24 \mathrm{hrs}$. On the test day, rats were injected with saline, placed in the center compartment, and allowed to roam the entire apparatus for $10 \mathrm{~min}$.

\section{Competing Conditioning}

After the cocaine place conditioning phase, rats were assigned to the Cocaine, Novelty, or Control group ( $n=12$ per group) with the restriction that groups did not vary on initial place conditioning scores (see Figure 1 for a schematic representation). This phase began $48 \mathrm{hr}$ after the test for cocaine place conditioning. In this phase, all rats were placed in each end compartment for $10 \mathrm{~min}$; these placements were separated by $24 \mathrm{hr}$ and alternated for 8 days. When rats were restricted to their previously paired compartment (i.e., cocaine compartment), they all received an injection of cocaine immediately before placement. When rats were restricted to their previously unpaired compartment (i.e., saline compartment), they also received an injection immediately before placement. However, the injection differed depending on the group. Specifically, rats in the Novelty group were injected with saline and had access to a different novel object (i.e., sock, PVC pipe, paint roller, or newspaper) for each placement. Rats in the Cocaine group received a cocaine injection $(7.5 \mathrm{mg} / \mathrm{kg})$ and rats in the Control group received a saline injection; these latter two groups did not have objects.

\section{Drug-Free and Drug-Challenge Test Days}

On the drug-free test day, rats were injected with saline, placed in the center compartment, and allowed to roam the entire apparatus for $10 \mathrm{~min}$. This test was conducted $24 \mathrm{hrs}$ after completion of the competing conditioning phase. On the drug-challenge test day ( $24 \mathrm{hrs}$ after the drug-free test), rats were given an injection of cocaine before placement in the center compartment and allowed free access to the entire apparatus for 10 min. The drug-free test preceded the drug-challenge test for all rats because our primary interest in this study was choice behaviors in a drug-free state.

\section{Results}

\section{Habituation}

Table 1 displays the means for the habituation session. On the habituation day, rats did not show a preference for the rod or hole flooring. More so, there were no differences between rats assigned to Control, Novelty, or the Cocaine groups. There was no main effect of Floor type, Group, or Group $\times$ Floor type interaction, $F \mathrm{~S}<1$. In addition, activity scores during the habituation session did not differ (Table 1). There was no main effect of Floor type, $F(1,33)=1.7, p=.2$, Group, $F<1$, or Group $\times$ Floor type interaction, $F(2,33)=1.3, p=.29$.

\section{Place Conditioning}

Figure 2 demonstrates that a preference for the cocainepaired compartment was observed for all three groups on the initial test of place conditioning. For Control rats (Figure 2A), this preference was maintained on both of the ensuing test days. This observation was supported by a main effect of Side, $F(1,11)=8.42, p=.014$, but no main effect of Test day, or Side $\times$ Test day interaction, $F s<1$. In contrast, Novelty rats only expressed a preference for the cocaine-paired side on the initial day of place conditioning (Figure 2B). Specifically, Novelty rats had a significant Side $\times$ Test day interaction, $F(2,22)=3.92, p=.035$. The amount of time spent on the paired side was significantly higher than the unpaired side on the test of cocaine place conditioning, Tukey $p<.05$. Similar to the Novelty rats, the rats in the Cocaine group only preferred the cocaine-paired side on the initial day of cocaine place conditioning (Figure $2 \mathrm{C}$ ). This preference was revealed by a significant Side $\times$ Test day interaction, $F(2,22)=4.41, p$ $=.023$. Significantly more time was spent on the paired side than the unpaired side on the test of cocaine place conditioning, Tukey $p<.05$.

\section{Activity}

Table 2 shows activity for rats in the Control, Novelty, and Cocaine groups for both compartments on the three different test days for Experiment 1. Rats in the Control group were more active on the unpaired side regardless of test day, main effect of Side, $F(1,11)=5.77, p=.035$. Additionally, there was main 
Phase 1: Cocaine Place Conditioning

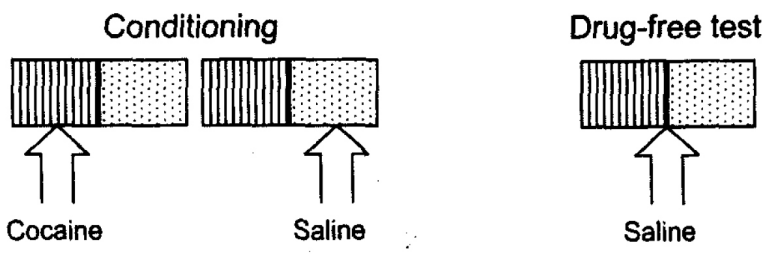

\section{Phase 2: Competing Conditioning}

Experiment 1

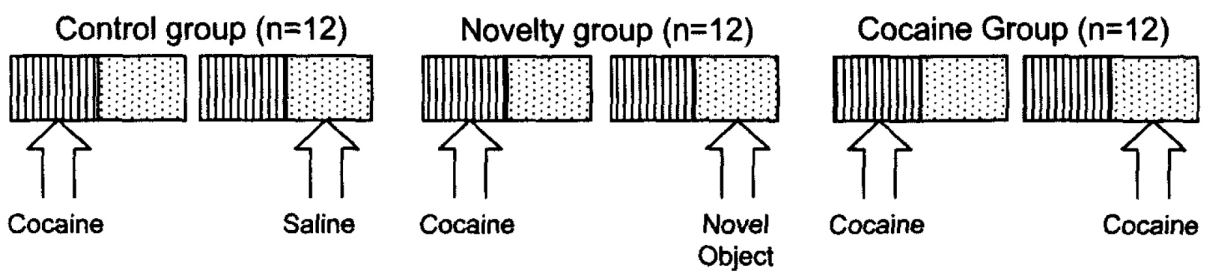

\section{Phase 2: Competing Conditioning \\ Experiment 2}

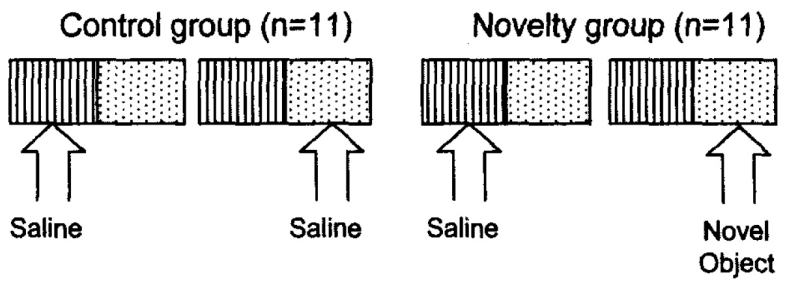

\section{Phase 3: Test Days}
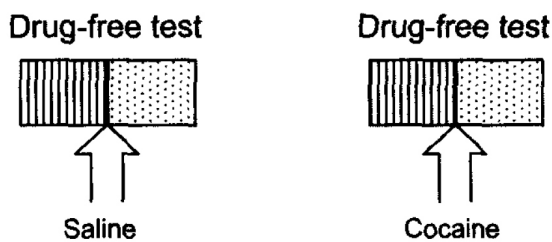

Figure 1. This figure shows a schematic representation of compartment placements throughout the sequential experimental phases for Experiments 1 and 2. Rats were conditioned in an unbiased apparatus and were assigned to conditioning groups in an unbiased fashion. Furthermore. compartment placements were counterbalanced according to rods/holes, spatial orientation, and whether drug pairing occurs on the first or second day of conditioning.

effect of Test day, $F(2,22)=5.99, p=.008$. Such that higher activity scores were observed on the drug-free and drug-challenge test days in comparison to the cocaine place conditioning test day, Tukey $p<.05$. However, there was not a Side $\times$ Test day interaction, $F<1$. Rats in the Novelty group also had a main effect of Test day, $F(2,22)=3.7, p=.041$. In particular, higher activity scores were observed on the drug-free and drugchallenge test days in comparison to the cocaine place conditioning test day, Tukey $p<.05$. For this group the main effects of Side and Side $\times$ Test day interaction were not significant, $F \mathrm{~s}$ $<$ 1.63. Like the Control group, rats in the Cocaine group were more active on the unpaired side regardless of test day, main effect of Side, $F(1,11)=5.6, p=.037$. Additionally, this group had a main effect of Test day, $F(2,22)=7.9, p=.002$. Specifically, higher activity scores were observed on the drug-free and drug-challenge test days in comparison to the cocaine place conditioning test day, Tukey $p<.05$. However, there was not a Side $\times$ Test day interaction, $F<1$. 
Table 1. Time Spent (Sec) and Activity Scores (Line Crosses/Time Spent) in Each Compartment on the Habituation Day for Experiments 1 and 2

\begin{tabular}{|c|c|c|c|c|}
\hline & \multicolumn{2}{|c|}{ Time in compartment } & \multicolumn{2}{|c|}{ Activity scores } \\
\hline & $\begin{array}{c}\text { Rod flooring } \\
(\text { mean } \pm S E M)\end{array}$ & $\begin{array}{c}\text { Hole flooring } \\
(\text { mean } \pm S E M)\end{array}$ & $\begin{array}{c}\text { Rod flooring } \\
(\text { mean } \pm S E M)\end{array}$ & $\begin{array}{c}\text { Hole flooring } \\
(\text { mean } \pm S E M)\end{array}$ \\
\hline \multicolumn{5}{|l|}{ Experiment 1} \\
\hline Control group & $257.9 \pm 8.06$ & $244.9 \pm 7.47$ & $0.101 \pm 0.006$ & $0.104 \pm 0.010$ \\
\hline Novelty group & $247.0 \pm 8.75$ & $254.9 \pm 9.06$ & $0.107 \pm 0.006$ & $0.106 \pm 0.010$ \\
\hline Cocaine group & $250.4 \pm 6.23$ & $246.7 \pm 7.54$ & $0.097 \pm 0.006$ & $0.116 \pm 0.010$ \\
\hline \multicolumn{5}{|l|}{ Experiment 2} \\
\hline Control group & $257.9 \pm 8.41$ & $246.5 \pm 9.75$ & $0.119 \pm 0.007$ & $0.118 \pm 0.007$ \\
\hline Novelty group & $261.2 \pm 5.94$ & $245.2 \pm 8.93$ & $0.115 \pm 0.006$ & $0.119 \pm 0.004$ \\
\hline
\end{tabular}

\section{Preference Ratios}

To compare shifts in compartment choice over test days between the groups, data were converted to preference ratios (Figure 3). There was a significant main effect of Test day, $F(2$, $66)=5.49, p=.006$, but not of Group, $F(2,33)=1.45, p=.25$, or a Group $\times$ Test day interaction, $F(4,66)=2.09, p=.09$.

\section{Conditioned Hyperactivity}

To test for cocaine conditioned hyperactivity comparisons were made between activity on the habituation and the initial cocaine conditioning test day for Experiment 1 (Figure 4A). There was not a main effect of Group, $F<1$, nor did Group interact with Test day or Side, Side $\times$ Group, Test day $\times$ Group, Side $\times$ Group $\times$ Test day interactions, $F \mathrm{~s}<1$. Thus, the groups did not differ in regards to conditioned hyperactivity before beginning the competing conditioning phase of the experiment. However, there was a main effect of Side, $F(1,33)=47.61, p=$ .001 , Test day, $F(1,33)=6.27, p=.017$, and a Side $\times$ Test day interaction, $F(1,33)=11.33, p=.002$. Follow up comparisons on the Side $\times$ Test day interaction found that on the cocaine place conditioning test, activity was increased on both sides (i.e., paired and unpaired) of the apparatus in comparison to the habituation day, Tukey $p<.05$. Moreover, this increase in activity was higher on the unpaired side of the apparatus than on the paired side.

\section{Discussion}

Rats in the Control group maintained a cocaine-conditioned preference throughout the three test sessions; this preference was not surprising given that cocaine pairings were continued during the second phase. It was surprising, however, that four 10-minute exposures with cocaine or novel objects in the previously unpaired compartment competed with an already established preference for the cocaine-paired side. This result was unexpected for two reasons. First, Novelty and Cocaine groups received twice as many conditioning trials on the cocainepaired side relative to the opposite compartment. Second, during the first phase, placements on the unpaired side exposed rats to the CS without the US (i.e., CS pre-exposure), which may delay the acquisition of a conditioned response (Albert \& Ayres, 1989). Both of these reasons predict that a preference for the original cocaine-paired compartment should be main- tained during the second experimental phase. Despite these factors, we found that in a free-choice situation, providing an alternative reward (i.e., cocaine or novelty) in an environment without preceding drug associations can influence choice behaviors. This competition between conditioned rewards was expressed as comparable preference for the end compartments for rats in the Novelty and Cocaine group. Importantly, increased motor activity does not account for this data pattern (see General Discussion). However, it is important to note that when data were converted to preference ratios, group differences were not detected. The competition between the conditioned rewards were only evident when data were analyzed using a within-subjects analysis. This data pattern suggests that the conditioned rewarding effects of cocaine retain some control over choice behavior when cocaine exposure continues in the competing conditioning phase (cf. Experiment 2).

\section{Experiment 2}

\section{Novelty Competition With Unpaired Exposure to Cocaine Conditioned Environment Procedure}

\section{Habituation and Cocaine Place Conditioning}

The procedures used in this phase were identical to those described for Experiment 1.

\section{Competing Conditioning}

After the cocaine place conditioning phase, rats were assigned to a Control or Novelty group ( $n=11$ per group) with the restriction that groups did not vary on initial place conditioning scores (see Figure 1 for a schematic representation). This phase began $48 \mathrm{hrs}$ after the test for cocaine place conditioning. In this phase, all rats received an injection of saline before placement in each end compartment for 10 minutes; these placements were separated by $24 \mathrm{hrs}$ and alternated for 8 days. When rats were restricted to their previously paired compartment (i.e., cocaine compartment), they merely experienced the drug-paired cues in the absence of the drug effect. When rats in the Novelty group were restricted to the previously unpaired compartment (i.e., saline compartment) they now had access to a different novel object (e.g., sock, PVC pipe, paint roller, newspaper) for each placement; rats in the Control group did not have objects. 

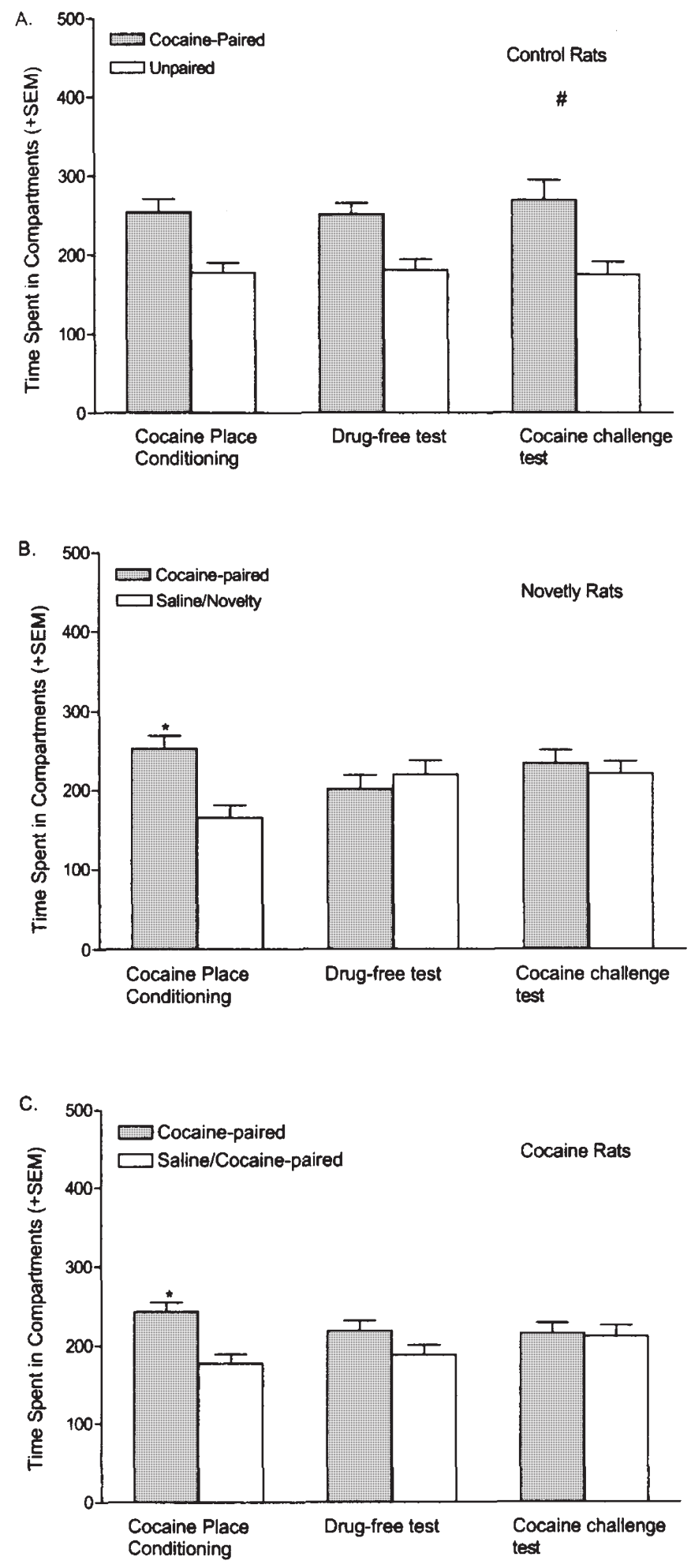

Figure 2. Mean time (in seconds) spent in each compartment for rats in the Control, Novelty, and Cocaine groups for the three tests of place conditioning in Experiment 1. Graph 2A shows the time spent in the cocaine-paired and unpaired compartments for all three test days for rats in the Control group. Graph 2B shows the time spent in the cocaine-paired and unpaired compartments for all three test days for rats in the Novelty group. Graph $2 \mathrm{C}$ shows the time spent in the cocainepaired and unpaired compartments for all three test days for rats in the Cocaine group. ${ }^{*}$ Significant main effect of Side $(p<.05) .{ }^{*}$ Significantly different from the unpaired compartment $(p<.05)$.
Drug-Free and Drug-Challenge Test Days

The procedures used for testing were identical to those in Experiment 1.

\section{Results}

\section{Habituation}

On the habituation day, rats did not show a preference for the rod or hole flooring (see Table 1). Further, rats assigned to the Control or Novelty group did not differ in compartment choice. Specifically, there was no main effect of Floor type, $F(1,20)=$ $1.41, p=.25$, Group, $F<1$, or Group $\times$ Floor type interaction, $F$ $<1$. Activity scores during the habituation session did not differ (Table 1), Floor type and Group main effects, and Group $\times$ Floor type interaction, $F \mathrm{~S}<1$.

\section{Place Conditioning}

Figure 4 demonstrates that a preference for the cocaine-paired compartment was observed for both groups on the initial test of place conditioning. For Control rats (Figure $5 \mathrm{~A}$ ), this preference was maintained on the ensuing test days. This observation was supported by a main effect of Side, $F(1,20)=10.05$, $p=.010$. These rats also had a main effect of Test day, $F(2,20)$ $=7.06, p=.005$, but post-hoc comparisons did not reach significance. The Side $\times$ Test day interaction was not significant, $F<1$. In contrast, Novelty rats had a significant Side $\times$ Test day interaction, $F(1,22)=3.92, p=.035$ (Figure 5B). Significantly more time was spent on the cocaine-paired side in comparison to the unpaired side on the initial day of place conditioning, Tukey $p<.05$. This group also had a main effect of Test day $F(2,20)=10.07, p=.001$, but post hoc comparisons did not reach significance. The main effect of Side was not significant, $F<1$.

Table 2. Activity Scores (Line Crosses/time Spent) in the Paired and Unpaired Compartments on the Habituation Day and All Test Sessions for Experiment I

\begin{tabular}{lcc}
\hline & $\begin{array}{l}\text { Initial paired } \\
\text { (cocaine) side } \\
\text { (mean } \pm \text { SEM) }\end{array}$ & $\begin{array}{c}\text { Initial unpaired } \\
\text { (saline) side } \\
\text { (mean } \pm \text { SEM) }\end{array}$ \\
\hline Control group $^{\mathrm{a}}$ & & \\
$\quad$ Cocaine place conditioning & \\
$\quad$ Drug-free test & $0.141 \pm 0.012$ & $0.172 \pm 0.016$ \\
$\quad$ Drug-challenge test & $0.166 \pm 0.019$ & $0.217 \pm 0.019$ \\
Novelty group & $0.168 \pm 0.015$ & $0.096 \pm 0.008$ \\
Cocaine place conditioning & $0.127 \pm 0.012$ & $0.163 \pm 0.016$ \\
$\quad$ Drug-free test & $0.195 \pm 0.019$ & $0.177 \pm 0.019$ \\
$\quad$ Drug-challenge test & $0.178 \pm 0.015$ & $0.189 \pm 0.021$ \\
Cocaine group & & \\
Cocaine place conditioning & & \\
Drug-free test & $0.148 \pm 0.012$ & $0.196 \pm 0.019$ \\
Drug-challenge test & $0.173 \pm 0.019$ & $0.196 \pm 0.019$ \\
& $0.203 \pm 0.015$ & $0.221 \pm 0.021$
\end{tabular}

Note ${ }^{\text {a }}$ Significant main effect of side; ${ }^{\mathrm{b}}$ Significant main effect of Test day. 


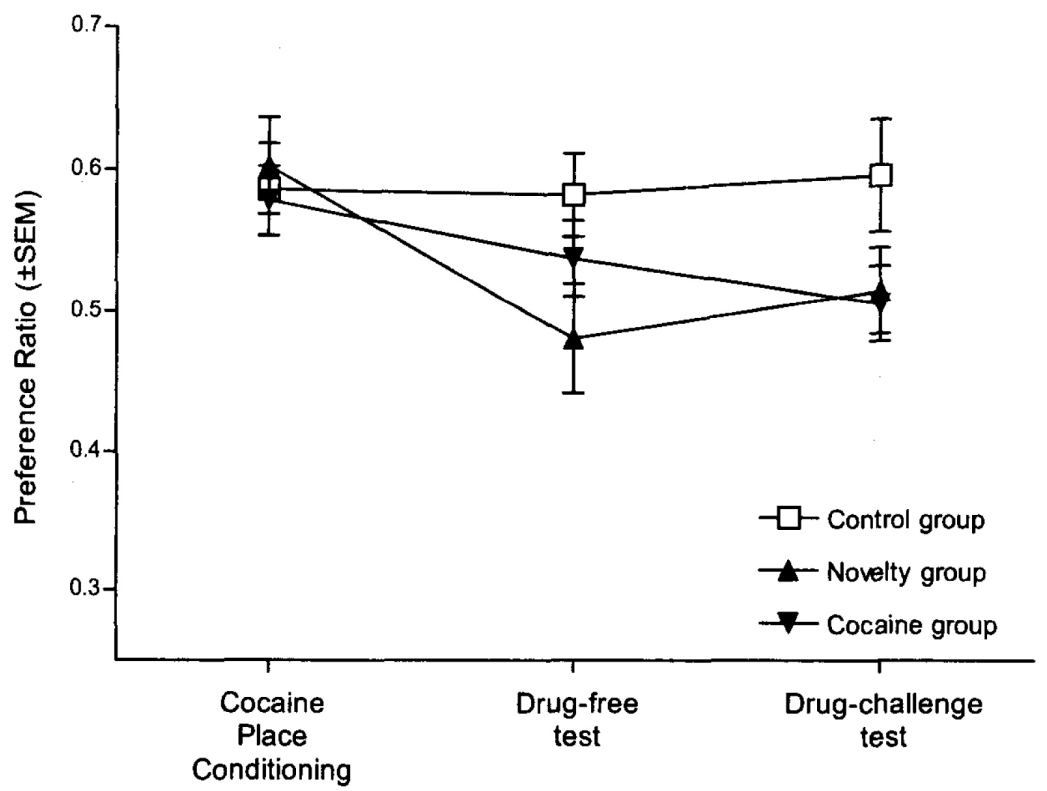

Figure 3. Mean preference ratios (time spent in cocaine-paired compartment/time in both end compartments) across test days in Experiment 1. This graph shows the comparison between rats in the Control, Novelty, and Cocaine groups across the three test days.

\section{Activity}

Table 3 shows activity for rats in the Control and Novelty groups for both compartments on the three different test days for Experiment 2. Rats in the Control group were more active on the unpaired side regardless of test day, main effect of Side, $F(1,20)=25.67, p=.001$. The main effect of Test day and Side $\times$ Test day interaction were not significant, $F \mathrm{~S}<1$. Rats in the Novelty group did not have a main effect of Side, $F<1$, but did have a significant main effect of Test day, $F(2,20)=5.29, p$ $=.014$, and a Side $\times$ Test day interaction, $F(2,20)=4.47, p=$ .025. However, post-hoc Tukey tests did not reach statistical significance.

\section{Preference Ratios}

To compare shifts in compartment choice between groups, data were converted to preference ratios. An omnibus analysis of preference ratios revealed a difference in compartment choice for rats in the Control and Novelty groups (Figure 6). Specifically, there was a main effect of Group, $F(1,20)=4.51, p$ $=.046$, a main effect of Test day, $F(2,40)=4.65, p=.015$, and a Group $\times$ Test day interaction, $F(2,40)=5.41, p=.008$. Pairwise comparisons revealed rats in the Control group had significantly higher preference ratios in comparison to rats in the Novelty group on the drug-free and drug-challenge test days, Tukey $p<.05$.

\section{Conditioned Hyperactivity}

To test for cocaine conditioned hyperactivity, comparisons were made between activity scores on the habituation and cocaine test days (Figure 4B). The results of this test replicated the preceding experiment. There was not a main effect of Group, $F<1$, nor did Group interact with Test day or Side, Side $\times$ Group $F(1$, 20) $=2.03, p=.17$, Test day $\times$ Group, Side $\times$ Group $\times$ Test day interactions, $F \mathrm{~S}<1$. Thus, the groups did not differ in regards to conditioned hyperactivity before beginning the competing conditioning phase of the experiment. However, on the cocaine place-conditioning test, activity increased in comparison to the habituation day. There was a main effect of Side, $F(1,20)=$ 62.19, $p=.001$, Test day, $F(1,20)=5.25, p=.033$, and a Side $\times$ Test day interaction, $F(1,20)=23.18, p=.001$. Follow up comparisons on the Side $\times$ Test day interaction revealed that on the cocaine place-conditioning test, activity was increased on both sides (i.e., paired and unpaired) of the apparatus in comparison to the habituation day, Tukey $p<.05$. Moreover, this increase in activity was higher on the unpaired side of the apparatus than on the paired side, Tukey $p<.05$.

\section{Discussion}

A compartment preference for the conditioned rewarding effects of cocaine was impacted by both novelty and cocaine pairings when cocaine exposure continued during the competing conditioning phase. However, from a drug-abuse perspective many addicts cease using drugs for a period of time when initially receiving treatment. Therefore, in Experiment 2 we discontinued cocaine treatment during the second experimental phase to emulate a drug-abstinence period (see Figure 1). Together, these results clearly demonstrate that the conditioned rewarding effects of novelty compete with those of cocaine when cocaine is withheld and cocaine-paired cues undergo procedural extinction. That is, for rats in the Control group, a preference for the cocaine-paired compartment remained; but conditioning with novelty competed with this preference such that the rats in the Novelty group split their time equally between environments. Importantly, when data were converted to preference ratios, the groups differed statistically after the competing conditioning phase. Thus, the combination of procedural extinction and novelty conditioning shifted compartment preferences when using a within-subjects analysis and reduced choice for the conditioned rewarding effects of the cocaine-paired environment in comparison to controls. 

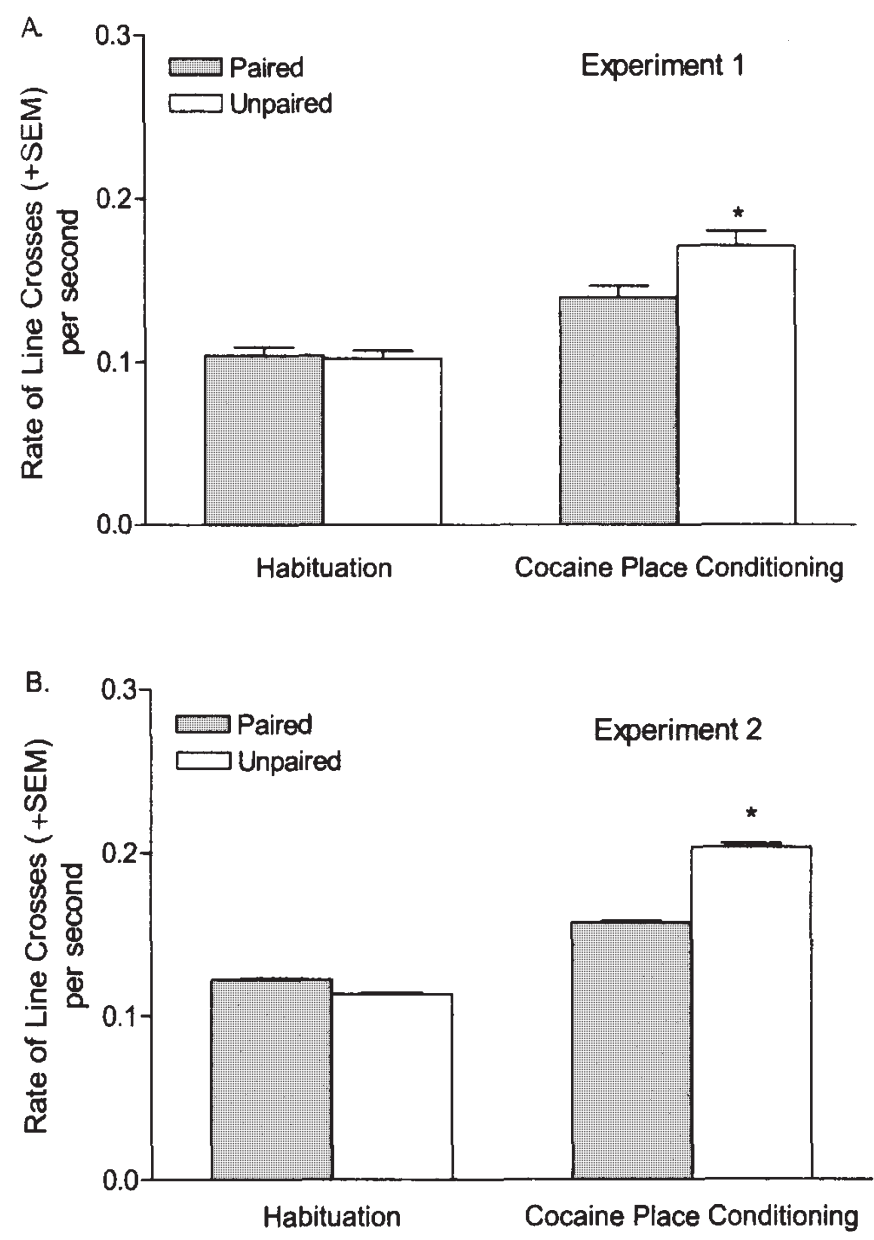

Figure 4. Mean activity scores on the paired and unpaired sides of the apparatus on the habituation and cocaine place conditioning test days for Experiments 1 (4A) and 2 (4B). This graph shows the test of cocaine conditioned hyperactivity. ${ }^{*}$ Significantly different from the cocaine-paired side.

\section{General Discussion}

Past research suggests that the behavioral and neurobiological processes underlying the pleasurable aspects of novelty appear to overlap with those of other rewards (Bardo, Donohew, \& Harrington, 1996; Bardo \& Dwoskin, 2004; Bevins, 2001; Bevins \& Bardo, 1999; Bevins et al., 2002; Cain, Saucier, \& Bardo, 2005; Dellu et al., 1996; Rebec et al., 1996). Such overlap leads to the prediction that novelty reward should compete with the rewarding aspects of stimulant drugs. Surprisingly, this prediction had not been tested in a choice situation until the present set of experiments. The present study demonstrated that approach behaviors elicited by the conditioned rewarding effects of novelty directly competed with conditioned approach behaviors controlled by cocaine-paired stimuli (Experiment 1). Moreover, this competition still existed when cocaine-paired cues underwent procedural extinction (Experiment 2) and when cocaine was in the central nervous system (i.e., drugchallenge tests, Experiments 1 and 2).

Procedural extinction to the cocaine-paired cues (i.e., cueexposure) was a seemingly important factor for novelty-conditioned reward to compete with that of cocaine. That is, the competition between conditioned rewards was more complete when the cocaine-paired cues were presented in the absence of the drug (Experiment 2) than when cocaine exposure was continued in the competing conditioning phase (Experiment 1). In the former case, competition was evident when data were compared both within and between subjects. In the latter, competition was only evident when data were compared within subjects. Notably, a significant interaction between Group and Side is not found, $p=.067$, if the analysis is made more comparable between the two experiments (i.e., include only the Control and Novelty group in the two-way ANOVA). Thus, a cue-exposure procedure (i.e., procedural extinction) produces more complete competition between the conditioned rewarding effects of cocaine and those of novelty.

We chose to test the competition between rewards in a sequential fashion (i.e., establish the cocaine preference first) primarily because intervention strategies treat patients who already have drug conditioning histories. However, the temporal
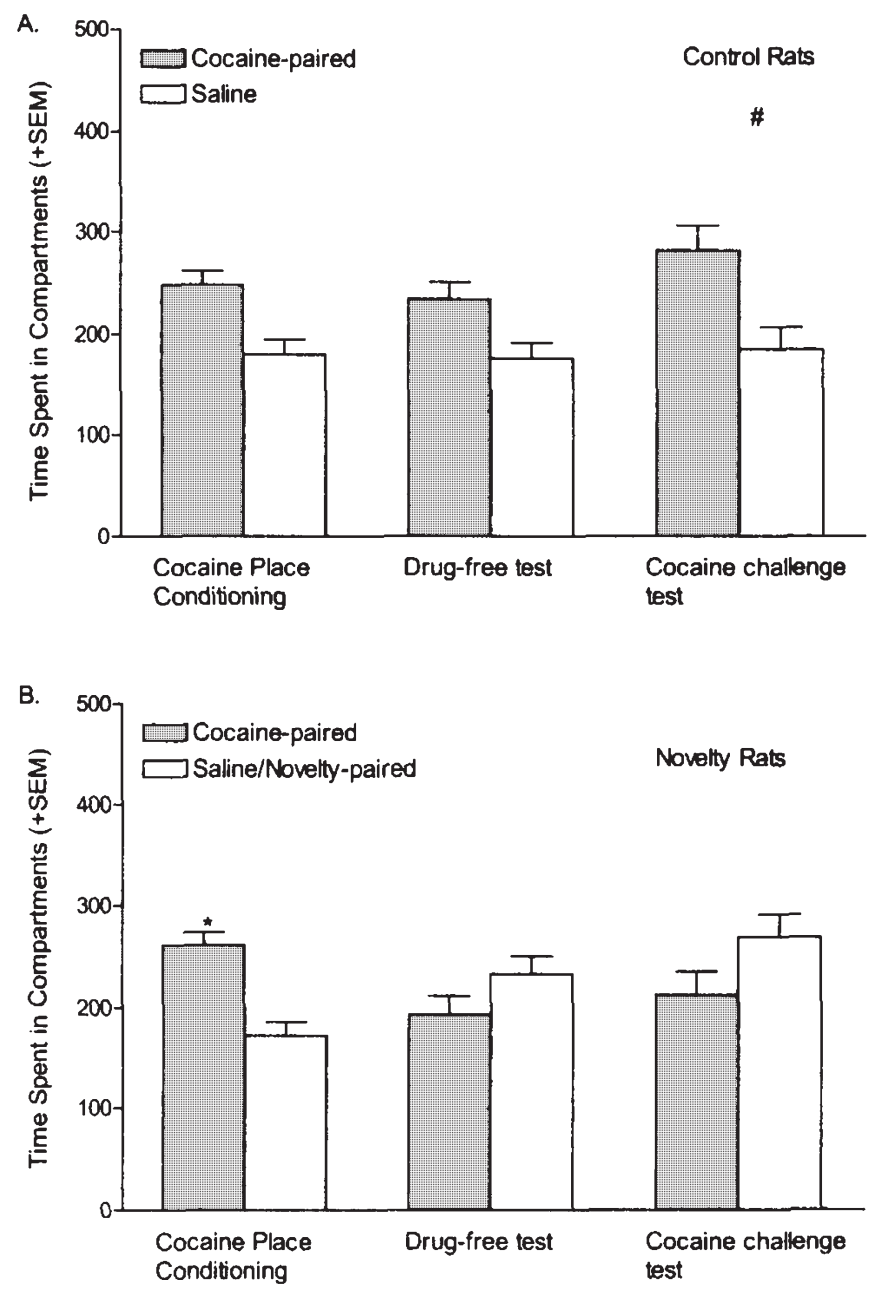

Figure 5. Mean time (seconds) spent in each compartment for rats in the Control and Novelty groups for the three tests of place conditioning in Experiment 2. Graph $\mathbf{5} \mathbf{A}$ shows the time spent in the cocaine-paired and unpaired compartments for rats in the Control group on the three test days. Graph $\mathbf{5 B}$ shows the time spent in the cocainepaired and unpaired compartments for rats in the Novelty group on the three test days. " Significant main effect of Side $(p<.05) .{ }^{*}$ Significantly different from the unpaired compartment $(p<.05)$. 
Table 3. Activity Scores (Line Crosses/Time Spent) in the Paired and Unpaired Compartments on the Habituation Day and All Test Sessions for Experiment 2

\begin{tabular}{llc}
\hline & $\begin{array}{c}\text { Initial paired } \\
\text { (cocaine) side } \\
\text { (mean } \pm \text { SEM) }\end{array}$ & $\begin{array}{c}\text { Initial unpaired } \\
\text { (saline) side } \\
\text { (mean } \pm S E M)\end{array}$ \\
\hline Control group $^{\mathrm{a}}$ & & \\
$\quad$ Cocaine place conditioning & $0.146 \pm 0.011$ & $0.192 \pm 0.019$ \\
$\quad$ Drug-free test & $0.153 \pm 0.016$ & $0.183 \pm 0.009$ \\
$\quad$ Drug-challenge test & $0.140 \pm 0.009$ & $0.193 \pm 0.018$ \\
Novelty group & & \\
Cocaine place conditioning & $0.166 \pm 0.012$ & $0.214 \pm 0.019$ \\
Drug-free test & $0.191 \pm 0.011$ & $0.159 \pm 0.016$ \\
Drug-challenge test & $0.236 \pm 0.021$ & $0.200 \pm 0.018$ \\
\hline
\end{tabular}

${ }^{a}$ Significant main effect of Side. ${ }^{b}$ Significant Side $\times$ Test day interaction.

profiles of cocaine and novelty conditioned reward imposes challenges to any design interested in competition among them. Of particular note, conditioning sessions with cocaine typically last 20 or 30 minutes (Brabant, Quertemont, \& Tirelli, 2005; Itzhak \& Martin, 2002; Kosten \& Miserendino, 1998; Mueller \& Stewart 2000; Zavala, Weber, Rice, Alleweireldt, \& Neisewander, 2003). In contrast, novelty conditioning sessions are typically 10 or 15 minutes given the transient nature of a novel stimulus (Besheer, Jensen, \& Bevins, 2002; Bevins \& Bardo, 1999; Bevins et al., 2002; Douglas, Varlinskaya,
\& Spear, 2003). As such, we used 30-min cocaine conditioning sessions in the first phase and 10-min novelty conditioning sessions in the second experimental phase. This procedure allowed us to assess changes in an already established reference to cocaine. Because we are exploring techniques to enhance intervention strategies that typically occur after a drug conditioning history has already been established, this point is of particular importance.

Some research suggests that conditioned locomotor activity resulting from repeated exposure to stimulant drugs within a specific context may confound tests of place conditioning (Swerdlow \& Koob, 1984; Veniza \& Stewart, 1987). Other studies demonstrate a dissociation between cocaine conditioned activity and place conditioning (Brabant, Quertemont, \& Tirelli, 2005; Kosten \& Miserendino, 1998; Martin-Iverson \& Reimer, 1996; Parker, 1992). Given the mixed findings, we evaluated activity (line crosses) in each compartment on the habituation and all test days. Consistent with other laboratories, rats were more active in their unpaired compartments in comparison to the paired compartments on the test of cocaine place conditioning (e.g., Martin- Iverson \& Reimer, 1996; Parker, 1992; Vezina \& Stewart, 1987). Accordingly, our cocaine place conditioning effect does not lend itself to a conditioned locomotor activity account for the induction of a place preference. Further support for dissociation between place conditioning and conditioned hyperactivity was provided with a direct test of conditioned hyperactivity. That is, comparisons were made between activity on the habituation and cocaine test days. Activity was increased on the test day; however, the effect was more profound on the un-

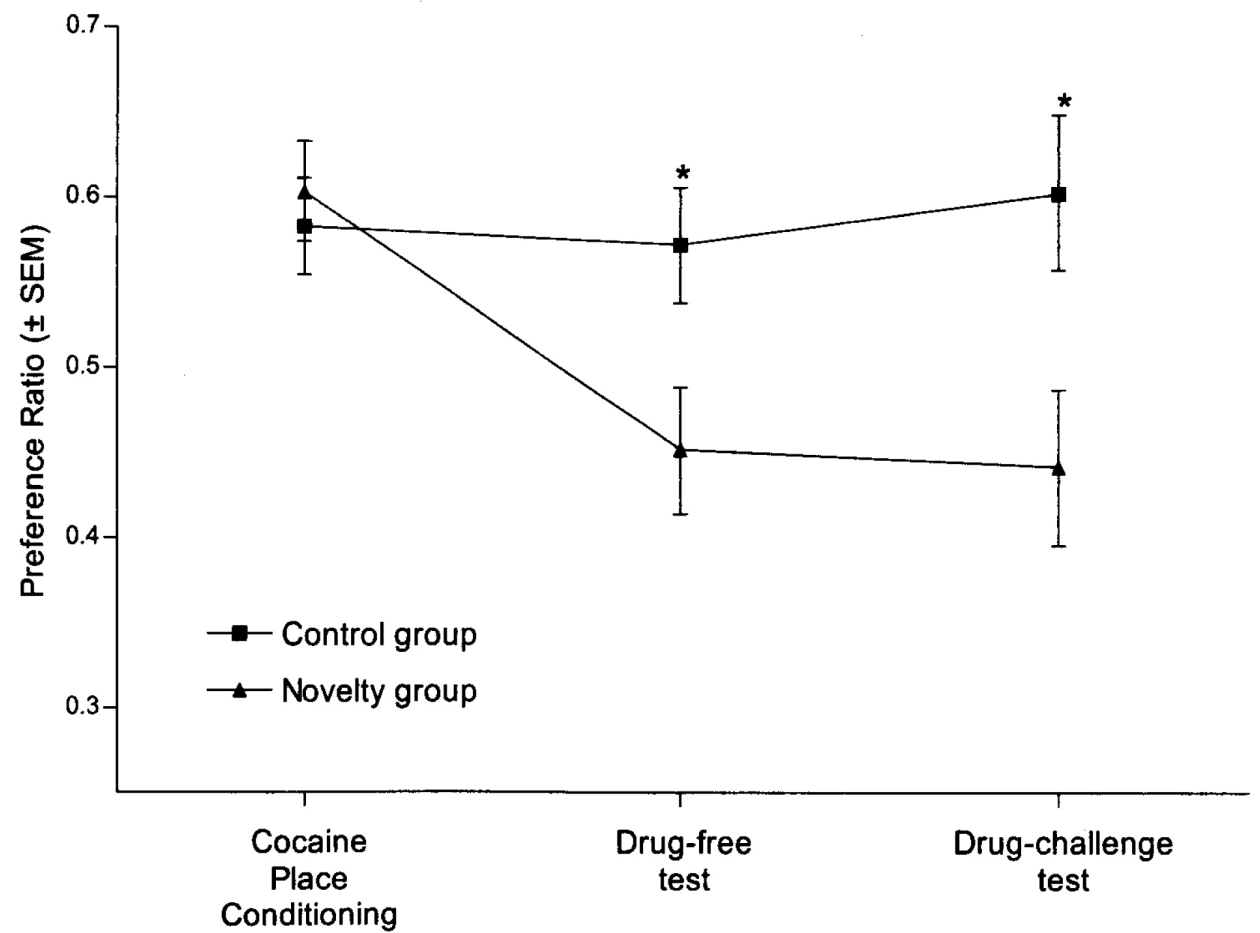

Figure 6. Mean preference ratios (time spent in cocaine-paired compartment/time in both end compartments) across test days for rats in the Control and Novelty groups in Experiment 2. This graph shows the comparison between rats in the Control and Novelty groups across the three test days. * Significantly different from rats in the Control group $(p<.05)$. 
paired side of the apparatus. A conditioned hyperactivity account would predict that more activity would have been evidenced on the cocaine-paired side.

Additional concerns have been expressed about the influence of motor activity on the expression of a compartment preference on place conditioning test days. Specifically, Gremel and Cunningham (2007) state that "disturbances or deficits in sensory-motor processes during the expression test might directly interfere with a subject's ability to approach and maintain contact with the stimulus." In Experiment 1 and 2 of the present report, a robust place conditioning response was observed for all groups on the initial test of cocaine place conditioning so it is unlikely that elevated activity impacted an approach response to the cocaine-paired environment. On the other hand, one could suggest that similar amounts of time spent in each compartment on the drug-free and drugchallenge test days could result from nonspecific motor alterations rather than a competition between the conditioned rewarding effects of cocaine and novelty. Because activity scores tended to be similar between groups the suggestion that decreased preference scores resulted from motor alterations is unlikely.

Researchers have suggested that exposure to novel stimuli may have clinical utility by acting as an effective substitute for drug reward (Bevins, 2001; Cain, Saucier, \& Bardo, 2005; D'Silva, Harrington, Palmgreen, Donohew, \& Lorch, 2001; Dellu et al., 1996). Specifically, novelty's ability to compete with cocaine may be a behavioral substitution strategy because environment-drug associations formed while abusing the substance continually impact choice behaviors during and after treatment programs. Providing alternative learning histories (i.e., new nondrug associations) during the intervention program may change choice behavior after an environmentdrug association is formed, thus easing the transition of some addicts from drug use to a drug-free lifestyle.

In conclusion, these studies provide empirical support for the idea that drug treatment programs may use novelty to enhance intervention programs by providing new learning histories that are incompatible with drug use. Albeit speculative, intervention strategies that incorporate novelty reward may have a greater impact on people classified as novelty and/ or sensation seekers (D'Silva et al., 2001). Personality constructs such as novelty seeking and sensation seeking rely on the premise that people seek out new and exciting situations because the outcomes are rewarding (Cloninger, 1987; Zuckerman \& Kuhlman, 2000). Zuckerman (1994) suggested that "an opportunity for sensation seeking often puts the person in an approach avoidance conflict where the rewards are positive sensations and experiences" (p. 124). The competition, described in this report, between conditioned rewards uses this appetitive approach behavior to demonstrate that conditioned rewards can compete to change choice behavior motivated by drug reward.

\section{References}

Albert, M., \& Ayres, J. J. (1989). With number of preexposures constant latent inhibition increases with preexposure CS duration or total CS exposure. Learning \& Motivation, 20, 278-294.
Anagnostaras, S. G., \& Robinson, T. E. (1996). Sensitization to the psychomotor stimulant effects of amphetamine: modulation by associative learning. Behavioral Neuroscience, 110, 1397-1414.

Bardo, M. T., \& Bevins, R. A. (2000). Conditioned place preference: What does it add to our preclinical understanding of drug reward? Psychopharmacology, 153, 31-43.

Bardo, M. T., Bowling, S. L., Robinet, P. M., Rowlett, J. K., Lacy, M., \& Mattingly, B. A. (1993). Role of dopamine D1 and D2 receptors in novelty-maintained place preference. Experimental and Clinical Psychopharmacology, 1, 101-109.

Bardo, M. T., Donohew, R. L., \& Harrington, N. G. (1996). Psychobiology of novelty seeking and drug seeking behavior. Behavioural Brain Research, 77, 23-43.

Bardo, M. T., \& Dwoskin, L. P. (2004). Biological connection between novelty- and drug-seeking motivational systems. In R. A. Bevins, \& M. T. Bardo (Eds.), Nebraska symposium on motivation: Vol. 5o. Motivational factors in the etiology of drug abuse (pp. 127158). Lincoln, NE: University of Nebraska Press.

Barr, G. A., Paredes, W., \& Bridger, W. H. (1985). Place conditioning with morphine and phencyclidine: Dose dependent effects. Life Sciences, 36, 363-368.

Besheer, J., \& Bevins, R. A. (2003). Impact of nicotine withdrawal on novelty reward and related behaviors. Behavioral Neuroscience, 117, 327-340.

Besheer, J., Jensen, H. C., \& Bevins, R. A. (1999). Dopamine antagonism in a novel-object recognition and a novel-object place conditioning preparation with rats. Behavioural Brain Research, $103,35-44$.

Bevins, R. A. (2005). The reference-dose place conditioning procedure yields a graded dose-effect function. International Journal of Comparative Psychology, 18, 101-111.

Bevins, R. A. (2001). Novelty seeking and reward: Implications for the study of high-risk behaviors. Current Directions in Psychological Science, 10, 189-193.

Bevins, R. A., \& Bardo, M. T. (1999). Conditioned increase in place preference by access to novel objects: Antagonism by MK-801. Behavioural Brain Research, 99, 53-60.

Bevins, R. A., Besheer, J., Palmatier, M. I., Jensen, H. C., Pickett, K. S., \& Eurek, S. (2002). Novel-object place conditioning: Behavioral and dopaminergic processes in expression of novelty reward. Behavioural Brain Research, 129, 41-50.

Bevins, R. A., \& Cunningham C. L. (in press). Place conditioning: A methodological analysis. In M. Anderson (Ed.), Tasks and techniques: A sampling of methodologies for the investigation of animal learning, behavior, and cognition. Hauppauge, NY: Nova Science Publisher.

Brabant, C., Quertemont, E., \& Tirelli, E. (2005). Evidence that the relations between novelty-induced activity, locomotor stimulation and place preference induced by cocaine qualitatively depend upon the dose: A multiple regression analysis in inbred C57BL/6J mice. Behavioural Brain Research, 158, 201-2 10.

Cain, M. E., Saucier, D. A., \& Bardo, M. T. (2005). Novelty seeking and drug use: Contribution of an animal model. Experimental and Clinical Psychopharmacology, 13, 367-375.

Cain, M. E., Smith, C. M., \& Bardo, M. T. (2004). The effect of novelty on amphetamine self-administration in rats classified as high and low responders. Psychopharmacology, 176, 129-138.

Cervo, L., \& Samanin, R. (1995). Effects of dopaminergic and glutamatergic receptor antagonists on the acquisition and expression of cocaine conditioning place preference. Brain Research, 673, 242-250. 
Cloninger, C. R. (1987). A systematic method for clinical description and classification of personality variants. A proposal. Archives of General Psychiatry, 44, 573-588.

Dellu, F., Piazza, P. V., Mayo, W., LeMoal, M., \& Simon, H. (1996). Novelty-seeking in rats: Biobehavioral characteristics and possible relationship with the sensation-seeking trait in man. Neuropsychobiology, 34, 136-145.

Di Chiara, G. (1999). Drug addiction as dopamine-dependent associative learning disorder. European Journal of Pharmacology, 375, 13-30.

Douglas, L. A., Varlinskaya, E. I., \& Spear, L. P. (2003). Novel-object place conditioning in adolescent and adult male and female rats: Effects of social isolation. Physiology \& Behavior, 8o, 317-325.

D’Silva, M. U., Harrington, N. G., Palmgreen, P., Donohew, L. D., \& Lorch, E. P. (2001). Drug use prevention for the high sensation seeker: The role of alternative activities. Substance Use \& Misuse, $36,373-385$.

Ehrman, R., Robbins, S., Childress, A., \& O’Brien, C. (1992). Conditioned responses to cocaine-related stimuli in cocaine abuse patients. Psychopharmacology, 107, 523-529.

Gremel, C. M., \& Cunningham, C. L. (2007). Role of test activity in ethanol-induced disruption of place preference expression in mice. Psychopharmacology, 191, 195-202.

Itzhak, Y., \& Martin, J. L. (2002). Cocaine-induced conditioned place preference in mice: Induction, extinction and reinstatement by related psychostimulants. Neuropsychopharmacology, 26, 130-134.

Kilts, C. D., Schweitzer, J. B., Quinn, C. K., Gross, R. E., Faber, T. L., Muhammad, F., et al. (2001). Neural activity related to drug craving in cocaine addiction. Archives of General Psychiatry, 58, 334-341.

Koob, G. F., \& LeMoal, M. (2001). Drug addiction, dysregulation of reward, and allostasis. Neuropsychopharmacology, 24, 97-129.

Kosten, T. A., \& Miserendino, M. J. D. (1998). Dissociation of noveltyand cocaine-conditioned locomotor activity from cocaine place conditioning. Pharmacology Biochemistry and Behavior, 6o, 785-791.

Martin-Iverson, M. T., \& Reimer, A. R. (1996). Classically conditioned motor effects do not occur with cocaine in an unbiased conditioned place preferences procedure. Behavioral Pharmacology, 7, 303-314.

McBride, W. J., Murphy, J. M., \& Ikemoto, S. (1999). Localization of brain progress and new issues. Progress in Neurobiology, 56, 613-672.

Mattson, B. J., Williams, S., Rosenblatt, J. S., \& Morrell, J. I. (2001). Comparison of two positive reinforcing stimuli: pups and cocaine throughout the postpartum period. Behavioral Neuroscience, $115,683-694$.

Mueller, D., \& Stewart, J. (2000). Cocaine-induced conditioned place preference: Reinstatement by priming injections of cocaine after extinction. Behavioural Brain Research, 115, 39-47.

National Research Council. (1996). Guide for the care and use of laboratory animals. Washington, DC: National Academy Press.

Palmgreen, P., Donohew, L., Lorch, E. P., Hoyle, R. H., \& Stephenson, M. T. (2001). Television campaigns and adolescent marijuana use: Tests of sensation seeking targeting. American Journal of Public Health, 91, 292-296.
Panksepp, J., Nocjar, C., Burgdorf, J., Panksepp, J. B., \& Huber. R. (2004). The role of emotional systems in addiction: A neuroethological perspective. In R. A. Bevins, \& M. T. Bardo (Eds.), Nebraska Symposium on Motivation: Vol. 5o. Motivational factors in the etiology of drug abuse (pp. 85-126). Lincoln, NE: University of Nebraska Press.

Parker, L. A. (1992). Place conditioning in a three- or four-choice apparatus: Role of stimulus novelty in drug-induced place conditioning. Behavioral Neuroscience, 106, 294-306.

Rebec, G. V., Grabner, C. P., Johnson, M., Pierce, R. C., \& Bardo, M. T. (1996). Transient increases in catecholaminergic activity in medial prefrontal cortex and nucleus accumbens shell during novelty. Neuroscience, 76, 707-714.

Robbins, S. J., Ehrman, R. N., Childress, A. R., \& O’Brien, C. P. (1997). Relationships among physiological and self-report responses produced by cocaine-related cues. Addictive Behaviors. 22, 157-167.

Robinson, T . E., \& Berridge, K. C. (2001). Incentive-sensitization and addiction. Addiction, 96, 103-114.

Sell, L. A., Morris, J. S., Beam, J., Frackowiak, R. S. J., Friston, K. J., \& Dolan, R. J. (2000). Neural responses associated with cue evoked emotional states and heroin in opiate addicts. Drug and Alcohol Dependence, 6o, 207-216.

Shaham, Y., Shalev, U., Lu, L., de Wit, H., \& Stewart, J. (2003). The reinstatement model of drug relapse: history, methodology and major findings. Psychophamacology, 168, 3-20.

Stephenson, M. T. (2003). Mass media strategies targeting high sensation seekers: What works and why. American Journal of Health Behavior, 27 (Suppl. 3), S233-S238.

Swerdlow, N. R., \& Koob, G. F. (1984). Restrained rats learn amphetamine-conditioned locomotion, but not place preference. Psychopharmacology, 84, 163-166.

Thompson, T., \& Ostlund, W. (1965). Susceptibility to readdiction as a function of the addiction and withdrawal environments. Journal of Comparative and Physiological Psychology, 6o, 388-392.

Tzschentke, T. M. (1998). Measuring reward with the conditioned place preference paradigm: A comprehensive review of drug effects, recent reinforcement mechanisms: intracranial self-administration and intracranial place-conditioning studies. Behavioural Brain Research, 101, 129-152.

Vezina, P., \& Stewart, J. (1987). Morphine conditioned place preference and locomotion: The effect of confinement during training. Psychopharmacology, 93, 257-260.

Wise, R. A., \& Bozarth, M. A. (1987). A psychomotor stimulant theory of addiction. Psychological Review, 94, 469-492.

Zavala, A. R., Weber, S. M., Rice, H. J., Alleweireldt, A. T., \& Neisewander, J. L. (2003). Role of the prelimbic subregion of the medial prefrontal cortex in acquisition, extinction, and reinstatement of cocaine-conditioned place preference. Brain Research, 990, 157-164.

Zuckerman, M. (1994). Behavioral expressions and biosocial bases of sensation seeking. New York: Cambridge University Press.

Zuckerman, M., \& Kuhlman, D. M. (2000). Personality and risk-taking: Common biosocial factors. Journal of Personality, 68, 999-1029. 